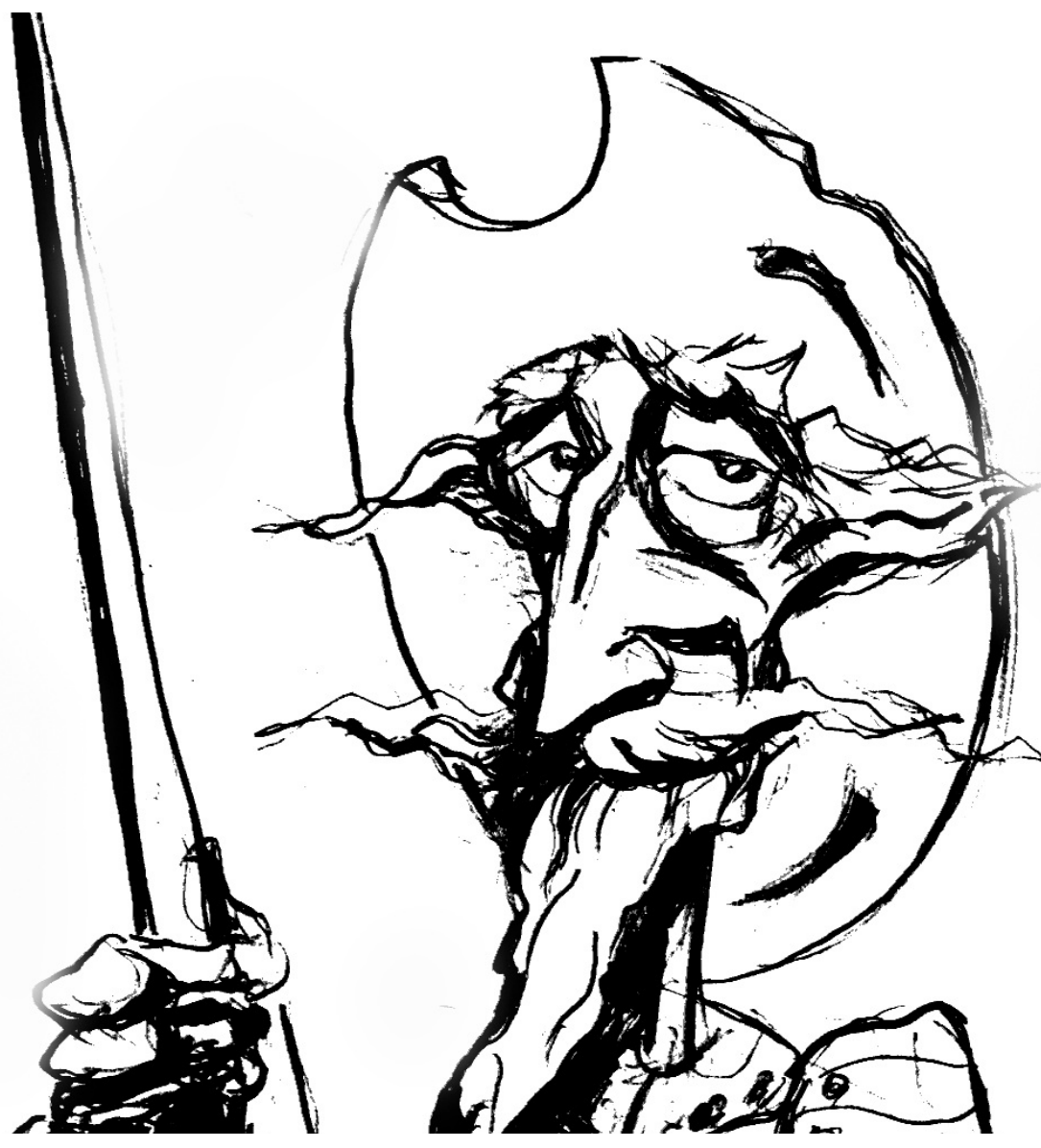

Los enviados por las ciudades reales de Cerdeña a su rey (siglos XIV-XIX). Una práctica continuada durante siglos

[Miquel Fuertes Broseta] 



\title{
Los enviados por las ciudades reales de Cerdeña a su rey (siglos XIV-XIX). Una práctica continuada durante siglos*
}

\author{
The Envoys by the Royal Cities of Sardinia to their King (14th-19th \\ Centuries). A Practice Continued for Centuries
}

\author{
MiQUEL FUERTES BROSETA
}

\section{Resumen}

Las ciudades reales del Reino de Cerdeña a lo largo de los siglos tuvieron que gestionar la casi permanente ausencia de sus reyes y señores. Para ello frecuentemente enviaron sus delegados para tratar asuntos de diversa índole con el monarca quien debía ser el centro de su gobierno. A lo largo del presente trabajo se exponen numerosos ejemplos de ello que permiten hacer un recorrido desde la conquista de la isla de Cerdeña por los reyes de Aragón y Cerdeña en los siglos XIV y XV hasta el fin del Regnum Sardiniae en 1847. Todo ello permite comprobar que las embajadas a la corte fueron una práctica reconocida y utilizada por las ciudades reales sardas durante más de cinco siglos.

\section{Palabras clave}

Ciudades; Cerdeña; Síndicos; Embajadores; Rey

\begin{abstract}
The royal cities of the Kingdom of Sardinia over the centuries had to manage the almost permanent absence of their kings and lords. In order to maintain contact with their sovereign, they frequently sent their delegates to discuss various matters with the monarch who had to be the center of their government. Throughout this work, numerous examples of this are exposed which allow us a journey from the conquest of the island of Sardinia by the kings of Aragon and Sardinia in the 14th and 15th centuries to the end of the Regnum Sardiniae in 1847. All this allows us to verify that embassies to the court were a practice recognized and used by the Sardinian royal cities for more than five centuries.
\end{abstract}

\section{Key Words}

Cities; Sardinia; Síndicos; Ambassadors; King

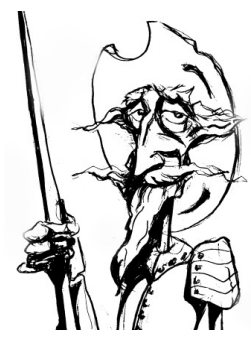

Recibido con pedido de publicación el 5 de marzo de 2021

Aceptado para su publicación el 20 de abril de 2021

Versión definitiva recibida el 14 de mayo de 2021

Miquel Fuertes Broseta, Università degli Studi di Cagliari, Cagliari, Italia; Universitat de València-Estudi General, Valencia, España; miquelfuertesbroseta@gmail.com

\footnotetext{
* El autor agradece a los evaluadores de revista Prohistoria sus comentarios, que han servido para mejorar el trabajo en diferentes aspectos.
}

Esta obra se publica bajo licencia Creative Commons. Atribución-NoComercial-CompartirIgual 4.0 Internacional 


\section{A modo de introducción ${ }^{1}$}

Aproximarse al mundo urbano puede ser una cuestión compleja, ya que al hablar de ciudad se pueden entender cosas muy distintas, tales como un lugar físico, un centro económico, cultural, jurisdiccional y también religioso o espiritual. Asimismo son espacios de residencia y de encuentro y de confluencia de individuos llegados por diversas circunstancias. Aquí abordaremos las ciudades como organismo o comunidad política.

En los últimos tiempos el papel de las urbes en la Monarquía hispánica es fruto de un buen número de estudios. Los planteamientos de Manuel Herrero (2017) de una "Monarquía de repúblicas urbanas" no hacen sino recordar la importancia del ámbito municipal en tanto que su jurisdicción, capacidad estatutaria y de negociación con el rey permite hablar de gobiernos republicanos.

En todo caso, la actividad de las ciudades como organización política es un tema que siempre ha interesado a los historiadores y en especial su relación con la Corona. Esto se halla bastante estudiado en el ámbito de la Corona de Aragón, en el que se debe incluir este estudio. Muestra de ello son obras clásicas como la de Jaume Vicens Vives (1936-1937) Fernando II y la ciudad de Barcelona (1479-1516) y el de Ernest Belenguer (2012) con una temática similar, pero centrado en la ciudad de Valencia. Los dos trabajos citados abordan la relación de un rey -de muchos señoríos- con una sola ciudad. El monarca se relacionaba con cada ciudad de forma directa e individual y a su vez la ciudad podía acudir personalmente a su rey y señor. Esa misma situación se repetía con cada una de las ciudades, reinos y señoríos del monarca.

Esa relación tan cercana hubiera sido sencilla si el soberano residiese en la ciudad, pero los reyes de Aragón estaban ora aquí ora allá en un continuo viaje entre sus distintos dominios. El advenimiento del emperador dificultó todavía más las visitas reales y, desde que Felipe II fijó la corte en Madrid, la ausencia fue ya casi permanente. De modo que la manera para mantener esa relación fue la vía epistolar y el continuo envío de representantes por parte de las ciudades al rey, de quien la urbe no podía esperar otra cosa que justicia y buen gobierno. Una necesidad que se hizo, si cabe, más evidente en Cerdeña

\footnotetext{
${ }^{1}$ Este trabajo se enmarca dentro del proyecto de investigación REDIF, Redes de información y fidelidad: los mediadores territoriales en la construcción global de la Monarquía de España (1500-1700), IP. Diego Sola e Ida Mauro (Ref. PID2019-110858GA-I00), financiado por el Ministerio de Innovación, Ciencia y Universidades. Asimismo se ha desarrollado gracias a un contrato predoctoral Ateneo de la Università degli Studi di Cagliari para el XXXIII ciclo de doctorado.
} 
que en otros reinos de la Corona de Aragón por ser uno de los "regnes servits de mar y que están molt apartats y lluny de sa magestat". ${ }^{2}$

\section{Las ciudades reales o brazo real de Cerdeña}

La unidad política de la isla de Cerdeña bajo un solo soberano y la "fundación" de un reino con el mismo nombre se debió a que fue conquistada militarmente por los reyes de la Corona de Aragón. Las campañas para tomar Cerdeña fueron largas pero, finalmente, se "creó" un nuevo reino independiente del resto de los territorios de la Corona de Aragón con los que compartía un mismo soberano. Nacía así un Regnum Sardiniae que sobrevivió hasta 1847, cuando se fusionó con los dominios que la dinastía Saboya gobernaba en la Península Itálica (Floris, 1999: 219-523). En todo ese tiempo, desde el siglo XIV hasta el XIX, Cerdeña nunca tuvo un soberano que lo fuese exclusivamente de la isla. Ello provocó que, dada la menor importancia del territorio en el sentido demográfico, económico y estratégico, los reyes en muy raras ocasiones visitaron el territorio insular. Esto se hizo especialmente evidente en el periodo en que Cerdeña formó parte de la Monarquía hispánica de los Austrias ya que, de todos los monarcas Habsburgo, tan sólo Carlos $\mathrm{V}$ visitó la isla, evidenciando que Cerdeña no era sino una pequeña provincia de un gran imperio (Manconi, 2012a: 9-16).

La unión aeque principaliter de los dominios del rey de Aragón significaba que diversos territorios compartían un mismo soberano pero manteniendo su autonomía política, lo que no excluía que el rey -y por tanto sus vasallostuviese una política exterior o dinástica común para todos sus señoríos. ${ }^{3}$ Esta situación se mantuvo después de la unión dinástica entre las Coronas de Castilla y Aragón que dio origen a la Monarquía hispánica (Anatra, 1987: 175464; Manconi, 1998: 179-194; 2010: 13-39). Por avatares del destino el reino de Cerdeña pasó a estar entre 1708 y 1718 bajo el gobierno del emperador Carlos VI -Carlos III de Cerdeña- que, aun después de que desapareciese la Corona de Aragón, siguió administrándola como un reino aparte (Guia, 2007: 403-414; 2008: 67-90). La misma dinámica se continuó con el acceso al trono sardo de la

\footnotetext{
${ }^{2}$ Instrucciones al síndico y conseller en cap Bernardí Armanyac en 1621. Archivio Storico del Comune di Cagliari [ASCC], Sezione Antica, 48. [N. de la E. En el presente artículo, debido a la cantidad de citas textuales en otras lenguas, excepcionalmente, las frases extensas no se reproducen en itálicas, tal como es el estilo habitual de esta publicación.]

${ }^{3}$ Las advertencias de Lalinde (1982: 29-50; 1994: 31-38; 1997: 433-460) sobre el uso del término Corona de Aragón y su organización política obligan a precisar conceptos sin aplicar modelos presentistas, por ello descarta términos como confederación y define el conjunto político como "pluralista coordinada". Utilizando fuentes bibliográficas este autor realizó una pequeña reflexión sobre las consecuencias, especialmente en el ámbito municipal, de la incorporación de Cerdeña a la soberanía de los reyes de Aragón y por tanto a su Corona (Lalinde, 1994: 273-279).
} 
dinastía Saboya en 1720 y continuó hasta la Perfetta fusione con la tierra firme en 1847 (Sotgiu, 2018: 359-391; Casula, 2016: 117-120).

De modo que los sardos tuvieron que convivir con una ausencia casi permanente de sus reyes durante más de cinco siglos. Una situación que compartieron con todas aquellas ciudades y territorios en los que sus soberanos estaban ausentes. Ello llevó a que se desarrollasen mecanismos similares para poder estar en contacto con sus gobernantes. Entre ellos estaba el contacto epistolar y también el envío de representantes a la corte donde residiese el soberano en aquel momento. Del mismo modo, los reyes delegaron en sus oficiales algunas funciones para poder administrar sus lejanos señoríos; en ese sentido se destacan los virreyes, más en el caso de Cerdeña por su temprana implantación. En 1324 se nombró el que para algunos autores fue el primer virrey, aunque con título de gobernador, mientras que en 1418 ya se instituyó una figura con nombre de "lochtinent de rey" o virrey como principal delegado del monarca (Loi, 1965: 20-30; Anatra, 1987: 134). Por lo que un mecanismo frecuentemente utilizado y muy poco estudiado fue acudir al virrey y al Real Consejo o a otros oficiales a solicitar el despacho de los asuntos, ya que si no podía resolverlo se encargaba de informar a la corte en donde era muy útil contar con su patrocinio.

Frecuentemente las mismas ciudades que enviaban personas para tratar con el monarca también hacían lo propio con su lugarteniente en la isla. En 1629 el Virrey escribió a Felipe IV que "Hipólito Are, jurado segundo y para este negocio sindico de la ciudad de Bosa" había acudido a su persona para denunciar que los intentos por vender la Planargia iban en contra de los privilegios de la urbe. ${ }^{4}$ Otra situación similar se observa en 1674 cuando Sassari, a través de "su jurado $3^{0}$ y síndico" solicitó al virrey que a cambio de un donativo de 6.000 escudos se concediese a los consellers de la ciudad jurisdicción sobre sus deudores. ${ }^{5}$

La existencia de otras vías de comunicación en ningún caso eliminó el derecho de los vasallos de poder acudir personalmente a su rey, ni tampoco la obligación de este de escucharlos -como sucedía también con los representantes de otros territorios y ciudades de la Monarquía hispánica (Calvo, 1993: 535-544; Álvarez-Ossorio, 2000, 227-358; Fuertes, 2019: 876-895; Mauro, 2020: 491-493).

\footnotetext{
${ }^{4}$ Carta de 6 de diciembre de 1629. Archivo de la Corona de Aragón [ACA], Consejo de Aragón, Leg. 1093.

${ }^{5}$ Años antes, la ciudad de Cagliari había negociado la compra de la jurisdicción sobre sus deudores y en aquel momento Sassari decidió hacer lo mismo. Este evento no responde a ninguna intención de la Corona por reformar el sistema jurisdiccional, sino a la voluntad del consell de Sassari de poder ejercer un mayor control sobre sus deudores. Es evidente que el rey estaba interesado en conceder esta jurisdicción dado que del cobro a los deudores dependían en gran medida las posibilidades de las ciudades de poder acceder a las continuas peticiones monetarias de la Corona. Informe de 10 de julio de 1674. ACA, Consejo de Aragón, Leg. 1108.
} 
Como es sabido, en Cerdeña, como en los otros reinos, al inicio de su reinado el monarca debía prestar juramento de respetar las leyes y privilegios y gobernar con justicia; a cambio, recibía la promesa de fidelidad y vasallaje del reino representado en sus tres estamentos. En la isla, dada la imposibilidad de que los reyes se desplazasen a hacer tal ceremonia, se creó un acto de toma de posesión en el que el virrey, por comisión especial del soberano, juraba y recibía el juramento de los brazos y ciudades, villas y lugares de realengo. Al finalizar la ceremonia los gobernadores de los castillos y los síndicos de las ciudades entregaban las llaves de las mismas como señal de que desde aquel momento el rey era su propietario, pero inmediatamente después el lugarteniente, en representación del rey las devolvía a los delegados de las urbes simbolizando que el monarca dejaba en manos de las ciudades su propio gobierno. ${ }^{6}$

Este evento nos sitúa en el tema central de este trabajo, las ciudades de Cerdeña y su relación con su soberano. Las ciudades reales sardas en los siglos XVII y XVIII eran siete: Cagliari, Sassari, Oristano, L'Alguer, Castellaragonés (actual Castelsardo), Iglesias y Bosa (Marongiu, 1979: 114-118). Estas urbes formaban el estamento o brazo real de Cerdeña que junto con los otros dos, eclesiástico y militar, formaban el cuerpo político del reino, del que el rey era cabeza. Por ello en los parlamentos o Cortes Generales del reino estas ciudades mandaban sus representantes y también tenían participación en diputaciones y juntas extraparlamentarias. Por otra parte, estos municipios eran estados feudales del rey, por lo que el monarca era su soberano, como lo era del conjunto del reino, pero también era su señor feudal. En consecuencia, el derecho que todo vasallo tenía de poder acudir al rey como fuente de gracia y justicia, en el caso de las ciudades del patrimonio regio era todavía mayor.

Las ciudades reales de Cerdeña estaban regidas mediante el sistema más extendido en la Corona de Aragón (Gil, 2008: 122-127; Anatra, 2008: 21-28; Guia, 2016: 385-406). Había en cada una de ellas un consejo restringido formado por un número variable según la urbe de consellers. Esta conselleria detentaba el gobierno ordinario de la ciudad. En sus funciones les asistían unos "elets" o "prohoms" en número de quince para las ciudades de Cagliari, Sassari y Oristán y más reducido para el resto de ciudades que actuaban como asesores. Había también un Consell Major o General, que variaba según el municipio entre 25 y 50 componentes fundados siguiendo el modelo del Consell de Cent de Barcelona cuya función era debatir y votar las propuestas de los consellers. La mayor parte de los asuntos ordinarios los resolvían los jurados y prohoms mientras que los extraordinarios o de mayor importancia se proponían y votaban por los Consejos Generales (Anatra, 2008: 21-28). En este sentido, los consellers podían, por ejemplo, escribir al rey, pero para enviar un delegado que

\footnotetext{
${ }^{6}$ Se conservan las actas de algunas de estas ceremonias en: Archivio di Stato di Cagliari [ASC], Antico Archivio Regio, Atti di presa di possesso del Regno di Sardegna (1665-1730).
} 
acudiese personalmente al soberano se votaba en Consejo General si era conveniente o no hacerlo, quién debía ser enviado y qué medios se emplearían para financiarlo. ${ }^{7}$

Hecha esta presentación general debemos centrarnos en el tema que nos ocupa, el envío de delegados por parte de los órganos de gobierno municipal de las ciudades reales del Reino de Cerdeña para entablar relaciones directas con el rey, una práctica que se perpetuó durante siglos. Desde el siglo XIV hasta el XIX un constante goteo de representantes se desplazó desde las ciudades reales de Cerdeña a la corte del rey, allá donde estuviese en cada momento. La figura del delegado fue evolucionando durante todo ese periodo, estableciéndose diferentes tipos y nombres como los de missatger, nuncio, legado, síndico, embajador, diputado o simplemente agente. En este trabajo se citan muchos de estos tipos, pero no se analizan en profundidad las características de cada uno y las diferencias entre ellos. El objetivo de este trabajo no es ahondar en los enviados, su perfil, privilegios o inmunidades, sino que se centra en el mecanismo y en su pervivencia plurisecular.

Este trabajo no solo es el primero que aborda de forma conjunta el envío de delegados al rey por parte de todas las ciudades reales del reino de Cerdeña, sino que también lo es al analizar de forma comparada el envío de representantes de urbes de un mismo reino o provincia de la Corona de Aragón y de la Monarquía hispánica. Su objetivo no es tanto analizar en profundidad los mecanismos de comunicación mediante delegados y su evolución, sino más bien constatar su existencia y su utilización a lo largo de los siglos, estudiando el tema desde la perspectiva de la larga duración y para todas las ciudades del reino. Hasta ahora la única aportación la había hecho Anna Maria Oliva (2004) en un trabajo sobre los representantes cívicos enviados a la corte por la ciudad de Cagliari en el siglo XV.

\section{Embajadores al rey: una tradición medieval}

La necesidad de recurrir personalmente al soberano era común y reconocida en el Antiguo Régimen. El soberano podía delegar algunas de sus funciones, pero no podía hacerlo con todas por estar unidas a sus huesos, por lo que siempre

\footnotetext{
7 A modo de ejemplo se pueden citar la carta de creencia de la ciudad de Sassari a su síndico Jerónimo Nuseo de 6 de junio de 1664. “El Consejo General desta ciudad de Sácer ha nombrado síndico para yr a essa real corte de vuestra magestad al padre fray Gerónimo Nuseo religioso capuchino para que besado que haya sus reales pies suplique por parte della muy humildemente a vuestra magestad confirmación de sus reales privilegios y capítulos que se decretaron en las ultimas cortes y represente por memoriales algunos negocios de consideración". ACA, Consejo de Aragón, Leg. 1104. Asimismo, el poder que el Consejo General de la ciudad de Cagliari "por quanto personalmente no pueden pareçer en la corte de su real magestad” dio a Antonio Mateo el día 20 de agosto de 1677. ACA, Consejo de Aragón, Leg. 1211.
} 
fue el último recurso en la gracia y en la justicia. Ello se hizo evidente muy pronto en Cerdeña.

La isla inició su vínculo de más de cuatrocientos años con la Península Ibérica en 1297 cuando el Papa Bonifacio VIII concedió la investidura del Reino de Cerdeña y Córcega a Jaime el Justo rey de Aragón, de Valencia y, en su calidad de conde de Barcelona, príncipe soberano de Cataluña. ${ }^{8}$ La campaña de conquista militar, debido a los costosos preparativos, no se inició hasta 1323 con la llegada al territorio insular del infante Alfonso, heredero a la corona (Casula, 1984: 8-19; Ortu, 2017: 19-41).

Sin embargo, parte del trabajo ya estaba hecho. El regente sardo de origen sasarés del Consejo de Aragón don Francisco de Vico en su Historia General del reyno de Serdeña, para justificar la fidelidad inmemorial de su ciudad natal, argumentaba que en 1306, mediante una delegación enviada a la ciudad de Barcelona, Sassari había decidido prestar "vasallaje voluntariamente". El marqués de Malaspina había reunido al consejo de ciudadanos de la urbe para diputar al "arçobispo turritano por nombre Theodorico al rey don Iayme como embaxador suyo el año 1306, el qual hizo muy bien el oficio, ofreciéndole toda su ciudad y distrito en nombre de los naturales della" (Vico, 1639: 7-9). Tiempo antes de que se iniciasen las operaciones militares para que la ciudad de Sassari hiciese una segunda embajada al monarca, en 1323 se envió a Miguel Pedro "cum litera credentiae" de Guantino Catón quien presidía entonces el gobierno del municipio. Estas muestras de fidelidad y compromiso fueron correspondidas con un real privilegio que confirmó las leyes y estatutos de Sassari. ${ }^{9}$

Las garantías legislativas de poder hacer este tipo de comunicaciones con el rey llegaron también muy pronto. Una de las primeras poblaciones pisanas en caer fue la villa de Chiesa, más tarde conocida como Iglesias, que en 1327 se convirtió en la primera en obtener el título de ciudad regia. En 1325 se tomó la villa de Bonaria que más tarde, cuando se unió con el Castillo, dieron lugar a Cagliari o Càller. El 1 de agosto de aquel año se concedió a Bonaria ser regida y tener un consistorio municipal como el de la ciudad de Barcelona. Lo mismo se concedió al Castillo tras la rendición de las tropas de Pisa en 1327 y el 25 de

\footnotetext{
${ }^{8}$ Se ha optado por denominar a los reyes de Aragón por su sobrenombre, ya que de otra manera podría haber confusión. En Jaime II el Justo, rey de Aragón, no habría otro problema más que confundirlo con Jaime II de Mallorca, pero veamos el caso de Pedro el Ceremonioso, que sería IV de Aragón, III de Cataluña, II de Valencia y I de Cerdeña. Sobre la cuestión de que Cataluña fue un principado con un conde como su soberano véase el reciente trabajo de Cristian Palomo (2020).

${ }_{9}^{9}$ Antonello Mattone expone que la versión de Vico no es del todo veraz, ya que la ciudad se había dividido en dos facciones, una filo-genovesa y otra filo-aragonesa. La victoria del bando aragonesista de Guantino Catón desembocó en esta mensajería para confirmar la fidelidad a Jaime II (Mattone, 1986: 418-419; Vico, 1639: 45-46).
} 
agosto se concedió a la que iba a ser capital de Cerdeña durante los siglos venideros el privilegio coeterum que extendía a Cagliari todos los privilegios de la ciudad de Barcelona (Sorgia y Todde, 1981: 12-13). Lo mismo se hizo con las ciudades de Sassari en 1331 y L'Alguer 1355 (Mattone, 1986: 420-424; 1994: 289297).

Con ello las ciudades adoptaban la organización municipal característica de la Corona de Aragón y heredaron de la ciudad condal otros muchos privilegios entre los que estaba el dado por Alfonso el Liberal el 5 de abril de 1286. En este el monarca había ordenado a todos sus oficiales que observaran las leyes y privilegios de la ciudad y, en caso de que no fuese así, daba potestad a los consellers de Barcelona para que "per vos et per universitatem Barchinone possitis facere et ordinare actores, síndicos vel procuratores ad conservationem dictorum privilegiorum, constitutionum et ordinationum et libertatum verborum contra quoscunque qui non observarent ipsa privilegia". ${ }^{10}$ Por consiguiente, las ciudades sardas vieron reconocido legalmente su derecho a acudir mediante sus delegados a la persona del monarca.

Una vez conseguido era fundamental conservar el derecho a acudir al rey y el mejor medio para lograrlo era hacer uso continuado del mismo. El privilegio Coeterum de 1331 que hizo extensivos los privilegios de Barcelona a Sassari se obtuvo gracias a una embajada enviada a Alfonso el Benigno. En 1336 la misma urbe envió a Miguel Amazelli a jurar fidelidad al nuevo rey Pedro el Ceremonioso (Vico, 1639: 69-76; Mattone, 1986: 18-19). Por entonces la ciudad de Cagliari también diputó algunos mensajeros al rey, dado que en 1328 se hizo una embajada a Alfonso el Benigno solicitando el respeto por los estatutos y ordenanzas de la ciudad (Oliva, 2004: 330) y en 1330 los consellers delegaron en Pedro Serra y Guillem Olzina para presentar algunas quejas sobre la actuación de los ministros reales (Vico, 1639: 65). En 1345 Pedro el Ceremonioso concedió a la universidad de Cagliari un privilegio que daba facultad de enviar embajadores siempre que se considerase oportuno, incluso sin licencia del gobernador de la isla (Pinna, 1903: 29; Oliva, 2004: 330).

Estas prácticas se continuaron en el siglo XV como demuestra el estudio de Anna Maria Oliva (2004) sobre los delegados de la ciudad de Cagliari. Para el resto de ciudades, es posible localizar algunos de ellos gracias a Vico y a algunas ediciones de documentos. Andrea Pergola (2020) ha transcrito la correspondencia sarda de Alfonso el Magnánimo conservada en el Archivo de la Corona de Aragón, lo que permite conocer la tarea de Bernat Martí Casademor, síndico de L'Alguer enviado al rey en 1417; Pere Ferrera mandado por la misma ciudad en 1418; o Pere de Blanch y Jaume Xarch comisionados por Cagliari un año después. Especialmente interesante es la embajada que hizo en

${ }^{10}$ El privilegio se ha localizado gracias a que don Jorge Carcasona lo utilizó para defender el derecho a hacer su embajada a Felipe IV en 1649. ACA, Consejo de Aragón, Leg. 1067, doc. 1/51. 
nombre de la ciudad de Cagliari el missatger Joan Collell a la llegada del Magánimo a la isla en 1420, "al qual, senyor, la vostra senyoria darà fe e crehença de la relació que fer-ne déu a vos senyor".

El proceso de incorporación de las ciudades al regio patrimonio continuó en el siglo XV. Tras la disolución del Judicato de Arborea en 1410, Bosa se agregó a la lista de urbes de jurisdicción real y ya en 1417 envió al síndico Nicolás Balbo a los pies del rey Alfonso. ${ }^{11}$

La apertura en 1421 de unas Cortes Generales al reino de Cerdeña a la que fueron convocadas las ciudades como brazo real, seguramente permitió encauzar muchas de sus demandas por esa vía, pero no impidió que las urbes enviasen embajadores al rey tras su clausura (Boscolo, 1993: 50-64). Sobre ello Anatra señala que en el periodo entre esas Cortes y las siguientes, ya bajo Fernando el Católico, las ciudades "en absència de la via parlamentaria, activen la de les ambaixades a la cort", el objetivo de esas comunicaciones no era otro que el mantenimiento de los privilegios y la obtención de otros nuevos que mejorasen la administración y regimiento urbanos (Anatra, 2008: 25). A tenor de lo expuesto en este texto se debe diferir de la interpretación de Anatra, dado que la ausencia de actividad parlamentaria no activó el mecanismo, pues había estado siempre activo, sino más bien se debe pensar que, a falta del ámbito asambleario, la actividad de estos enviados se hizo más necesaria.

En 1448 la Corona conquistó una nueva ciudad, Castelgenovese, futura Castellaragonés, a los Doria (Fossati, 2007: 446-447; Ferrante, 2007: 542-552) y con ello se llega a los albores de la época moderna con un brazo real compuesto por las ciudades de Cagliari, Sassari, L'Alguer, Iglesias Castelgenovés y Bosa hasta que esta última fue de nuevo infeudada en 1468. Todas las ciudades reales contaban con el derecho reconocido de enviar sus representantes al monarca, tanto porque habían heredado privilegios de la ciudad de Barcelona que así lo garantizaban como porque lo hacían con frecuencia.

Queda hasta ahora bastante comprobado que las ciudades reales del reino de Cerdeña durante los siglos XIV y XV enviaron numerosos delegados a tratar asuntos de diversa índole con su rey. Los temas a tratar principalmente fueron la obtención de privilegios y estatutos y la defensa de los mismos. Ello es especialmente interesante por el hecho de que estos negociadores fueron enviados en un periodo en que Cerdeña no había sido completamente conquistada y pacificada; en definitiva, lo que se estaba haciendo mediante estos delegados era negociar el regimiento de un reino en construcción y en sus primeras décadas de andadura, por lo que era necesario dialogar y tratar sobre

\footnotetext{
${ }^{11}$ En lo tocante al privilegio de Alfonso el Magnánimo se concedía por la "humil suplicació per lo feel nostre en Nicholoso de lo Balbu, síndich tramés a nostra cort per part de vosaltres, nostres consellers, promens e universitat". Resulta también destacable la transcripción de la carta de creencia destinada al rey, redactada en sardo (Tasca, 1999: 261-262).
} 
cuáles eran los mejores medios para garantizar el buen gobierno de las ciudades y el mantenimiento de la paz pública. La necesidad de llegar a acuerdos con el reino y las ciudades venía dada por la imposibilidad del rey de imponerse por la fuerza y de ejercer él mismo o mediante sus delegados el gobierno de las urbes y del conjunto del reino, la única vía viable era llegar a acuerdos con las élites locales entre las que se encontraban las oligarquías que detentaban los gobiernos municipales.

En ese sentido, la condición de ciudades de realengo, es decir ciudades propiedad del rey, implicaba que era el monarca, como señor de vasallos, quien debía impartir justicia y garantizar el buen gobierno de la ciudad tarea que, como hemos visto, mediante estas continuas negociaciones fue dejando en manos de organismos de gobierno municipal. Para tal fin era necesario el establecimiento de pactos que dieron lugar a estatutos cívicos y privilegios. En definitiva, una negociación continua entre el rey y los representantes de la comunidad urbana con el fin de establecer las normas de regimiento más satisfactorias para todas las partes.

\section{Los primeros pasos de dos "nuevas" ciudades reales a través de sus mensajeros}

Durante la Edad Moderna la necesidad de las ciudades de enviar sus delegados al monarca continuó. Hasta la unión dinástica entre las coronas de Castilla y Aragón, tan solo cinco de las siete ciudades que llegaron a formar el brazo real tenían al rey como su señor feudal. En el proceso de incorporación de las dos últimas ciudades tuvieron un papel destacado los nuncios enviados por los consistorios municipales al soberano. Conviene señalar que las dos ciudades que vamos a tratar se incorporaron al patrimonio regio tras la unión dinástica, pero ello no cambió de forma sustancial la manera en que los sardos se relacionaban con su rey. Como es sabido, Cerdeña fue unido a la Corona de Aragón de forma igualitaria a los otros reinos, ello no se modificó con la unión con Castilla, por lo que Cerdeña siguió siendo en la Edad Moderna un reino unido aeque principaliter al cuerpo de la Monarquía Católica.

En 1409 la victoria de las tropas de la Corona comandadas por Martín el Joven, rey de Sicilia y heredero a la Corona de Aragón, supuso el punto de inflexión que finalmente provocó la extinción del Judicato de Arborea. Sin embargo, algunos señoríos en lugar de incorporarse al patrimonio del rey fueron infeudados y se creó el marquesado de Oristán y el condado de Goceano. En 1470 moría Salvador Cubello, último descendiente directo de la familia a quien se había infeudado el marquesado, por lo que la sucesión al título de Leonardo de Alagón fue impugnada por el virrey Nicolau Carròs. Ello inició una serie de enfrentamientos judiciales y militares. En 1478 el Virrey tomó la ciudad de Oristán y en 1482 los tribunales se pronunciaron en favor de 
la Corona. Desde entonces los reyes de la corona de Aragón y de la Monarquía hispánica incorporaron a su larga lista de títulos los de marqués de Oristán y conde de Goceano (Anatra, 1987: 179-190; Ortu, 2017: 339-351).

Justo al inicio del reinado de Fernando el Católico en 1479 se incorporó al patrimonio de la corona otra ciudad en Cerdeña. Oristán hasta hacía apenas 70 años había sido la capital del Judicato de Arborea y, por ello, capital de un principado independiente. Poco tiempo después de ser conquistada por las tropas del rey, la ciudad envió un emisario para solicitar al monarca la confirmación de algunos privilegios y la erogación de otros nuevos. Para ello la universidad y prohombres de Oristán eligieron a Joan Passio "civem dicte civitatis, nuncium ad maiestatem nostram".

Fruto de la tarea de este delegado en Zaragoza, donde estaba el rey, es el privilegio de 12 de agosto de 1479 en el que el que la ciudad suplicaba al rey que "li placia voler-los atorgar en forma de privilegi e ley pactionada les coses següents". Las concesiones reglaban muchas cuestiones del funcionamiento de la ciudad. Se solicitó que al incorporarse al patrimonio real no se disgregase el marquesado y que "la ciutat de Oristany e los tres Campidanos sien units perpetualment" y si se hiciese algún acto en contrario los habitantes del marquesado no estuviesen obligados a obedecerlo y si fuese necesario defenderse "mà armada". A lo que el Rey accedió. Asimismo, también se pidió que para regir la ciudad cada año se sorteasen cinco consellers, lo que el soberano aceptó dándoles el mismo poder que los de la ciudad de L'Alguer. Se suplicó que los consellers pudiesen cobrar un derecho sobre el vino para financiar su actividad y además se les diese licencia para que junto con el podestà y diez prohombres pudieran imponer cualquier impuesto tal como hacía la ciudad de Cagliari. El Rey accedió a la súplica, pero advirtiendo que para imponer gravámenes debía preceder licencia del virrey. Se concedió también a los consellers y podestà jurisdicción civil y criminal que podía ser apelada ante el rey. Se aprobaron otros muchos capítulos sobre el abastecimiento, sobre las inmunidades y franquezas de los habitantes, etcétera; ya que "dites coses redunden e redunderan en hutilitat, prosperitat y augment de vostra reyal corona de la qual vostres vassalls e devotissíms subdits de tot lo dit marquesat speren resurrectió e vida" (Uccheddu, 1998: 73-83).

Tres días más tarde ante una nueva súplica de Joan Passio se redactó un nuevo privilegio en el que se reglamentaba el funcionamiento y modo de elección de los oficios de gobierno de la ciudad, pues su Majestad había mandado que la ciudad y los campidanos "sien perpetuament unides e yncorporades a la Corona reyal de Aragó e de Serdenya". El documento 
recogía, por tanto, la manera de regirse del municipio, cuales debían ser los oficios, la manera de elegirse por "sach sive sort", sus competencias, etcétera. ${ }^{12}$

Vemos, pues, que cuando se incorporó al patrimonio del rey la ciudad de Oristán recurrió a enviar un nuncio para que el soberano estableciese las normas de actuación y de relación con el soberano a las que debían atenerse en los siglos venideros.

Con la incorporación de Oristán eran ya seis las ciudades reales del reino, faltaba una última por sumarse. La ciudad de Bosa se había incorporado por primera vez al patrimonio de la Corona en 1410 tras la desaparición del Judicato de Arborea, de modo que en los años siguientes se le concedieron los privilegios que debían regular su forma de gobierno siguiendo el modelo del resto de ciudades. Sin embargo, en 1468 Juan II de Aragón concedió a Juan Villamarí la enfeudación de la ciudad y la Planargia, por lo que dejó de formar parte del realengo. La línea de descendencia directa de los Villamarí se extinguió en 1559 con la muerte de Isabel de Cardona Villamarí, princesa de Salerno. De manera similar a como había pasado décadas antes con Oristán, aunque la princesa había dejado sus señoríos a María de Cardona, el emperador Carlos V ordenó el secuestro del feudo. Tras varios conflictos judiciales y negociaciones, en 1565 se llegó a un acuerdo para que la corona comprase a los herederos los derechos sobre Bosa y la Planargia, volviendo así a incorporarse al regio patrimonio (Tasca, 1999: 69-80; 2012: 43-64).

La situación fue notablemente diferente con la de Oristán; Bosa ya había sido una ciudad real, por lo que una de las primeras cuestiones a abordar fue la confirmación de sus privilegios y de su regimiento municipal. En 1566 con poder delegado de Felipe II -Felipe I en Cerdeña- Alexio Nin juró en nombre del soberano los privilegios, estatutos, capítulos y buenas costumbres de la ciudad de Bosa (Tasca, 1999: 192-193). En consecuencia, la universidad de Bosa, el sistema de regimiento que se había diseñado a principios del siglo XV, debía seguir plenamente vigente y había sido confirmado. Por tanto, el objetivo de los enviados a la corte por Bosa no fue establecer un contrato con el rey sino que el ya existente se observase.

En 1568 acudió a Segovia, donde se encontraba Felipe II, Juan Antonio Sallent "sýndico a nos embiado por los consellers de nuestra ciudad de Bosa". Parece ser que Sallent entregó dos memoriales al rey pidiendo el respeto por algunos privilegios y la concesión de otros nuevos. Destaca entre las diversas súplicas la que toca a la jurisdicción de la Planargia. El síndico solicitaba que se respetase el conocimiento de las causas contra los oficiales de la Planargia que

\footnotetext{
12 Además de las copias citadas por Uccheddu (1998:105-113) en la transcripción del documento conservadas en el Archivio del Comune di Oristano y en el Archivio di Stato di Cagliari se ha localizado una copia en la Cancillería del Archivo de la Corona de Aragón. ACA, Cancillería, Reg. 3586, ff. 55-59.
} 
debían ser juzgados por el podestà y consellers de la ciudad, lo que el Monarca aceptó mandando que "tengan el mismo dominio y jurisdictión sobre la dicha Planargia que en tiempo pasado han acostumbrado". ${ }^{13}$

En 1472 Saturnino Ursena era el representante de la ciudad de Bosa en Madrid. En aquella ocasión el problema a tratar radicaba en que, en tiempos del dominio de la princesa de Salerno, varios particulares y la propia ciudad habían contraído compromisos de pago por mandato de la princesa, de modo que siendo ahora el rey el señor feudal de la ciudad le correspondía cargar con las obligaciones del antiguo propietario. Finalmente, Felipe II accedió a pagar la parte que debía aportar del patrimonio regio (Tasca, 1999: 294-296). Esta es una situación que merece ser destacada por el hecho de que la embajada al rey se hacía no en su calidad de monarca, sino por su condición de señor feudal y heredero de las obligaciones contraídas por los antiguos feudatarios.

Entre 1579 y 1580 Julián Ursena, hijo de Saturnino, fue enviado como síndico para solicitar la confirmación de varios privilegios, como el respeto a la jurisdicción de los consellers, las garantías para sus comerciantes o sus franquicias en el comercio del coral. Asimismo, se solicitó al rey, como era su obligación, la mejora de las defensas y puerto de la ciudad. Conviene recordar que era obligación del rey defender a sus vasallos y estos debían ayudarlo en esa tarea. En aquella ocasión se trató también de hacer una reforma en el gobierno municipal mudando el oficio de podestà por un veguer con su asesor, como lo tenían Cagliari y Sassari (Tasca, 1999: 296-309).

Con ello vemos que en la incorporación de dos nuevas ciudades al patrimonio regio, se empleó el mismo mecanismo para entablar un diálogo con el soberano. En el caso de Oristán el objetivo era la obtención de privilegios y solicitar al monarca un sistema con el cual la ciudad pudiese gestionarse, mientras que en el caso de Bosa, que ya había sido una ciudad de realengo anteriormente, la tarea fue obtener la confirmación de sus privilegios y que el soberano asumiese las obligaciones que había contraído al convertirse en señor feudal de la ciudad. En ambos casos el rey otorgó a los gobiernos municipales control y jurisdicción sobre el territorio circundante, en el caso de Oristán sobre el marquesado y Campidanos y en el caso de Bosa sobre la Planargia, lo que provocaría numerosos conflictos jurisdiccionales en las décadas posteriores tanto con el procurador real a quien correspondía la administración del Regio Patrimonio en la isla, como con la Real Audiencia, tribunal que desde su creación a finales del siglo XVI debía ejercer como más alta instancia de justicia en el reino.

${ }^{13}$ Cecilia Tasca (1999: 289-293) transcribió las cartas de respuesta de Felipe II a estos memoriales que se encuentran en ACA, Cancillería, Reg. 4332, ff. 17-21. 
Con todo, lo que nos interesa destacar en este trabajo es que la práctica medieval de enviar emisarios para establecer pactos con el rey continuó en la época moderna cuando Cerdeña y la corona de Aragón formaban parte de la Monarquía hispánica.

\section{Siete ciudades y sus aparatos de representación (siglos XVI-XVII)}

Con la incorporación de Bosa a las posesiones de la Corona el brazo real del reino de Cerdeña pasó a estar compuesto por siete ciudades y así se mantuvo hasta el siglo XIX. Conviene recordar que Cerdeña nunca había sido un reino en el que el rey estuviese presente de forma estable y por ello el mayor absentismo regio provocado por la Unión Dinástica y el posterior establecimiento de la Corte en Madrid debió tener un impacto menor que en el resto de los reinos de la corona de Aragón. Tampoco la creación del aparato polisinodial debió modificar sustancialmente la relación entre el rey y sus vasallos sardos, ya que desde antaño el rey había contado con un Consejo Real que se transformó en el Consejo de Aragón (Arrieta, 1994: 26-87). ${ }^{14}$

Es cierto que la política de redreç fernandina -ya iniciada por su padre Juan II- afectó los gobiernos municipales de Cerdeña en los que también se introdujo la insaculación como medio de acceso a los cargos de gobierno de la ciudad, medio que fue extendido a todas las ciudades, incluso a las nuevas ciudades reales citadas de Oristán y Bosa. Más allá de eso se puede decir que la inclusión de la corona de Aragón dentro de la Monarquía hispánica afectó poco a la forma en que se gobernaban las ciudades sardas (Anatra, 1987: 207-225).

Dado que en los siglos XVI y XVII la práctica de enviar delegados al rey era muy antigua, se practicaba con frecuencia y estaba reconocida por leyes y privilegios, el regente sardo del Consejo de Aragón Francisco de Vico defendía:

"His relictis, quaeso sit tibi circa, proregis authoritatem compertum, quod nec regno nec alicui ex universitatibus licet nuntios, legatos seu oratores quos embaxatores appellamus ad regem mittere illius licentia non obtenta [...] hanc autem licentiam sine iusta causa prorex denegare non potest $[. .$.$] alias$ petita et non obtenta poterint regnum et civitates suos mittere legatos"' (Vico, 1714: 36).

Las ciudades de Cerdeña podían participar políticamente y relacionarse con el rey en tres niveles: como ciudad, como parte del estamento real o como

\footnotetext{
${ }^{14}$ Algunos autores como Joan Reglà (1973: 72), Jon Arrieta o más recientemente Xavier Gil (2016: 31-58) han planteado que el funcionamiento institucional de la Monarquía hispánica se diseñó utilizando el modelo de la Corona de Aragón, por lo que es lógico que la introducción del sistema polisinodial supusiese pocas novedades para los reinos de aquellos territorios.
} 
parte del reino de Cerdeña. Eso se deja ver a través de los embajadores o síndicos enviados durante o tras los parlamentos o Cortes Generales.

En algunas Cortes, especialmente a mediados y finales del siglo XVII, se enviaron síndicos en nombre de todo el reino, es decir representando a los tres brazos de las Cortes. En ese sentido estos enviados eran también delegados de las ciudades regias por actuar en nombre del brazo real. Este es el caso de don Juan de Castellví, marqués de Láconi y el canónigo Diego de Acorra en el parlamento Avellano de 1642-1643 (Murgia, 2006: 43-90); también de don Félix Brondo, marqués de Villacidro y don Jaime Carta durante las Cortes presididas por el conde de Lemos en 1655-1656; de don Agustín de Castellví, marqués de Láconi, en 1667; 15 del mercedario fray Diego Pinna en 1677 (D'agostino, 2009: 50) y de don Juan Francisco de Castellví, marqués de Láconi, en 1688 (Francioni, 2015: 189).

En otras asambleas el brazo real nombró como portavoz ante el rey a la misma persona que eligió el estamento militar como ocurrió en las Cortes de Montellano en 1699 cuando se diputó a don José Zatrillas, marqués de Villasalto (Catani y Ferrante, 2004: 58-67). Asimismo, en el parlamento Elda de 1603 Melchor Dexart fue seleccionado como síndico únicamente por el estamento real, es decir por el conjunto de las siete ciudades y también síndico de la ciudad de Cagliari (Doneddu, 2015:1101-1308).

Que las ciudades unidas como estamento real pudiesen nombrar un diputado que hablase en nombre de todo el brazo o de todo el reino no excluía que cada una de ellas tuviese capacidad de enviar a su propio representante. Esto era especialmente interesante en las súplicas de capítulos particulares de cada ciudad. En las Cortes Generales sardas se acostumbraba a que cada ciudad real o incluso los apéndices de Cagliari, campidanos de Oristán y otras encontradas reales presentasen sus capítulos que eran suplicados por el conjunto del estamento para que el virrey y el rey los decretasen. En algunas ocasiones el alto interés que la ciudad tenía en su aprobación le llevaba a diputar a su costa a un síndico para que los solicitase al rey. Así pues podemos ver que en el parlamento de 1511 la ciudad de Cagliari envió a Joan Nicolau Aymerich, la de Sassari a Joan Rois de Caltena, L'Alguer a Miquel Benet de Gualbes y Castellaragonés a Francisco Rebolledo (Oliva y Schena, 1998: 741795). En las Cortes de 1518 Cagliari diputó a Miquel Botes y de nuevo a Joan Nicolau Aymerich, Sassari a Ángel Marongiu y Joan Antoni Milà de Gambella, Oristán a Jaume Vinxi, L'Alguer a Miquel Moner e Iglesias delegó también en

${ }^{15}$ Las actas de estos dos parlamentos no han sido todavía fruto de edición en la serie Acta Curiarum de modo que se debe acudir a las actas conservadas en los archivos. La nómina de Carta y Villacidro por el brazo real en 1656 en: ASC, Antico Archivio Regio, Parlamenti, vol. 172, f. 135. El nombramiento de Láconi en 1666 por el estamento real en: ASC, Antico Archivio Regio, Parlamenti, vol. 176, f. 246. 
Miquel Boter (Galoppini, 2016: 107-731). En la mayoría de Cortes del siglo XVI se observa que la situación se mantuvo por lo que no nos detendremos más en ello, tan solo citar que en 1530 en las Cortes presididas por el virrey Martín Cabrero la ciudad de Sassari nombró como síndicos, además de a Juan Fernando de Soto, a Fernando y Juan Cabrero, hijos del entonces virrey (Galoppini, 2016: 887-889).

No obstante, la necesidad de comunicarse con la corte y con el rey no se agotaba en el ámbito parlamentario. Hay un número notable de ejemplos en que las ciudades sardas tuvieron que acudir mediante sus portavoces allá donde se encontraba el rey para tratar de asuntos muy diversos.

En 1560 una carta de Felipe II al maestre racional de Cerdeña revela lo que "el sýndico de essa ciudad [Oristán] me ha hecho entender". Enviando un emisario al rey los consellers de Oristán pretendían que el oficio de prior de la ciudad quedase vacante y que sus rentas fuesen para financiar el hospital de la urbe. Asimismo, solicitaban que se respetase la costumbre de que los arrendamientos y alquileres de tierras del marquesado se hiciesen con acuerdo del procurador real y del conseller en cap, por tanto, mediante acuerdo entre rey y ciudad. El enviado también solicitó la ayuda del rey en fortificar la ciudad. ${ }^{16}$ Como es sabido, la defensa del reino o de la ciudad era una función compartida entre el rey y los vasallos, en el acto del juramento real el monarca prometía proteger al reino y este correspondía comprometiéndose a ayudarle.

Ese mismo año, 1560, el monarca escribía a la ciudad de Sassari que "lo síndic de la nostra ciutat de Sàsser davant nos y en aquest Supremo Consell ha humilment proposat". El Supremo Consejo al que se hacía referencia no era otro que el Consejo de Aragón, adaptación al sistema polisinodial del antiguo Consejo Real de los reyes de la Corona de Aragón que había sido estructurado por el Ceremonioso (Arrieta, 1994: 26-87). En aquella ocasión la ciudad de Sassari suplicaba licencia al rey para retrasar la persecución de los arrendadores del cobro del donativo que debía pagar la ciudad, ya que pequeñas dilaciones en los depósitos provocaban que los consellers tuviesen que enviar alguaciles a perseguir a los arrendatarios con un gran gasto para la ciudad, a lo que el Rey accedió permitiendo una dilación de un mes antes de iniciar estas medidas. ${ }^{17}$ Como es conocido, gran parte de la financiación de la Monarquía dependía de los donativos "voluntarios" que reinos y ciudades hacían al rey cumpliendo con su obligación de vasallos de asistir al monarca en su tarea, por lo que a Felipe II

\footnotetext{
16 Felipe II al maestre racional. Toledo, 3 de junio de 1560. ACA, Cancellería, Reg. 4324, ff. 91v92r. Felipe II al virrey. Toledo, 3 de junio de 1560. ACA, Cancillería, Reg. 4325, f. 18r.

17 Rey a los consellers de Sassari. Toledo, 17 de junio de 1560. ACA, Cancillería, Reg. 4324, ff. 113v-114v. También dos cartas al virrey de 8 de octubre de 1560. ACA, Cancillería, Reg. 4325, f. $98 \mathrm{r}$.
} 
le interesaba que las ciudades tuviesen los medios suficientes para poder recaudar ese dinero con el mínimo gasto posible en el proceso.

También en 1560 la ciudad de Bosa, secuestrada entonces por la Corona, diputó dos representantes a Toledo, Juan Cubello y Juan Salaris, conseller en cap de la ciudad. ${ }^{18} \mathrm{Al}$ año siguiente era Cagliari la que enviaba un síndico para solicitar la aplicación de un privilegio que Alfonso el Magnánimo había otorgado a la ciudad. ${ }^{19}$ Se observa, por tanto, que en los primeros dos años desde el advenimiento de Felipe II la comunicación de las ciudades sardas con su rey y señor era frecuente. Se podrían citar otros muchos ejemplos pues la misma situación se ve repetida año tras año y lo evidencian los estudios de Manconi (2012b).

Hasta ahora hemos visto que con mucha frecuencia las urbes sardas debían acudir donde estuviera el rey ya fuese en parlamentos en forma de reino, brazo o ciudad y también en los periodos entre Cortes. Sin embargo, la mayoría de los temas que aquí se han expuesto tanto en el ámbito parlamentario como fuera de él son asuntos que debía resolver el monarca como rey y señor feudal por la vía del gobierno o de la gracia, es decir eran súplicas, y que estaba en manos del soberano conceder o no según considerase más justo y conveniente. No obstante, las ciudades sardas, en tanto sus gobiernos ejercían jurisdicción, debían acudir a la corte también a pleitear. El Consejo Supremo de Aragón era tribunal superior de justicia para el reino de Cerdeña como también lo era para Valencia y Baleares, no así para Aragón y Cataluña. De modo que en último grado de apelación las causas judiciales de las ciudades llegaban a la corte (Arrieta, 1994: 521-599). Con el tiempo, dadas la dilación y acumulación de las causas, se hizo necesario que las ciudades contasen con delegados permanentes en la corte regia. Estos representantes son lo que conocemos como agentes permanentes o síndicos permanentes, que con frecuencia fueron utilizados también para introducir negocios no necesariamente judiciales.

El aparato de representación de las ciudades sardas en la corte, no parece diferir demasiado del descrito por David Bernabé (2007: 31-57; 2008) para la ciudad de Orihuela, ni tampoco con otros expuestos por Alberto Ángulo (2010; 2016; 2019) y Antonio Álvarez-Ossorio (1997; 2000) para otros territorios de la Monarquía hispánica. Ello resulta muy evidente en el caso de la ciudad de Cagliari, capital del reino, en la que los fondos conservados permiten hacer una reconstrucción aproximada de su agencia en la corte desde finales del siglo XVI. Entre los agentes o síndicos permanentes de Cagliari podemos destacar a Gavino Penducho Carta, natural de la ciudad, pero que también actuó como

\footnotetext{
${ }^{18}$ Cartas del rey al virrey de 23 de junio y 1 de septiembre de 1560. ACA, Cancillería, Reg. 4324, ff. $161 \mathrm{r}-161 \mathrm{v}$.

${ }^{19}$ Rey al virrey. Madrid, 20 de septiembre de 1561. ACA, Cancillería, Reg. 4325, ff. 228v-229r.
} 
agente o síndico en la corte de otras instituciones. ${ }^{20}$ Tal vez la documentación de otros archivos municipales permita localizar a otros agentes, pero aun así es posible constatar la existencia de tales agencias para otras ciudades a través de la documentación del Consejo de Aragón en la que encontramos personajes como Antonio Corellas que fue síndico o agente permanente de las ciudades de Oristán, Iglesias y Bosa durante las décadas de 1610 y $1620 .{ }^{21}$

La existencia de un representante permanente en la corte y en concreto en el Madrid de los Austrias debía permitir que los negocios se introdujesen en el Consejo de Aragón de una manera más fluida y con un coste mucho menor que enviar un síndico o embajador desde Cerdeña. Estos individuos cobraban una cifra fija anual de 50 ducados, un salario muy bajo pero que los permitía subsistir en Madrid ya que como exponía Bernabé se trataba de profesionales de la representación que al gestionar a la vez los asuntos de varias ciudades, corporaciones y particulares acumulaban varios salarios (Bernabé, 2008: 433434).

Aunque todos los municipios contasen con un agente permanente en Madrid nunca se renunció ni se dejaron de enviar delegados extraordinarios. Diputar síndicos o embajadores para un asunto en concreto tenía otras ventajas para las ciudades: 1 . Mostraba al rey lo importante que era para la ciudad el asunto a tratar; 2. La ciudad se hacía presente en la corte con entrada y audiencia pública con el soberano; 3 . Se podía enviar a una persona experta o implicada en el caso; 4. Se podía diputar a una persona de prestigio o a un miembro del consistorio. Por todas o algunas de estas cuestiones las urbes optaron por sumar a su representación ordinaria en la corte de los Austrias el goteo de representantes extraordinarios de diverso perfil.

\section{La tarea de los enviados extraordinarios en sus instrucciones}

Para aproximarnos a la tarea de los representantes extraordinarios de las urbes sardas conviene atender a algunas de las instrucciones que se les otorgaron para dirigir su tarea. Aquí se han utilizado dos: la primera es la que la ciudad de Iglesias dio en 1582 a Miquel Otger "síndich elegit per a sa magestat";22 la segunda data de 1621 y la redactó la ciudad de Cagliari para el conseller en cap Bernardí Armanyac. ${ }^{23}$

\footnotetext{
20 Sabemos que era natural de Cagliari por diferentes expresiones en diferentes documentos como en uno que los consellers de Cagliari se declaraban "tan servidores de vuestra merced como lo es verdadero hijo de su patria y como aquella ha resivido de su mano tanto benefisio a tiempo de sus antecesores". Carta de 21 de diciembre de 1641. ASCC, Sezione Antica, 81.1.

${ }^{21}$ Diversos documentos repartidos en: ACA, Consejo de Aragón, Leg. 1225, 1226 y 1227.

22 Archivo del Congreso de los Diputados [ACD], Cerdeña, H-01-021-0412 U.I.2

${ }^{23}$ ASCC, Sezione Antica, 48.
} 
Las dos instrucciones contienen, antes de los capítulos, un encabezamiento en el que se identifica al destinatario, es decir al síndico. Las de 1582 incluyen algunas expresiones que expresan "la grandíssima confiança de lo poble de esta ciutat" por "ser la persona de la qualitat, és patriotta el qual està al cap de tot". En las de 1621 se decía que se había elegido como síndico al conseller en cap en reunión del Consejo General y con licencia del virrey. En ambos casos vemos que se enviaba una persona natural de la ciudad e informada de los asuntos, en el caso de Otger por ser patriota y estar "al cap", es decir, al frente de todos los asuntos y en el de Armanyac por ser ni más ni menos que el conseller en cap de la ciudad de Cagliari "cap y clau" del fidelísimo reino de Cerdeña.

El primer punto de ambos documentos estipulaba que lo primero que el síndico debía hacer era tener audiencia con el rey, besar sus pies y manos y entregar la carta de creencia. En el caso de Otger en 1582 debía suplicar al rey "mane apiadar-se desta sua ciutat manant alçar la mà en los negocis occorrents". La instrucción a Armanyac es todavía más interesante pues era la primera vez que la ciudad de Cagliari enviaba un síndico desde el acceso al trono de Felipe IV por lo que se le encargó "besar sos reals peus y mans per part de esta sa fidelíssima ciutat de Càller offerint-li tota aquella ab les paraules de major effecte y amor que puga". Las ciudades sardas y en especial la capital acostumbraban a enviar sus embajadores en cada advenimiento, como muestra Vico (1639) a lo largo de su obra. Esto se ve especialmente en el periodo de la Guerra de Sucesión cuando se envió por parte de Cagliari y otras ciudades al conde de Montesanto como síndico a Felipe V de Castilla y IV de la Corona de Aragón en 1700; cuando la ciudad fue conquistada por las tropas austracistas en 1708, Cagliari envió a Barcelona, donde se hallaba Carlos III de Habsburgo, al secretario Gavino Carnicer. ${ }^{24}$

La segunda tarea de los síndicos debía ser tener audiencia con algunos cortesanos. Las de 1582 ordenaban que se besase las manos a los señores del Consejo de Aragón mientras que las de 1621 mandaban que se hiciese lo propio con el vicecanciller, el confesor del rey y las demás personas que conviniese para el negocio a tratar. En definitiva se indicaba al enviado que se entrevistase con las personas que iban a intervenir en la resolución de los negocios o que podían influir en la opinión del rey: es decir el confesor real y el vicecanciller y demás regentes del Consejo de Aragón.

El tercero y siguientes capítulos de ambos documentes pasan a instruir al emisario sobre los asuntos que debía introducir al rey. Ello servía para

\footnotetext{
${ }^{24}$ Cartas de los consellers de Cagliari a los consellers de Bosa, Iglesias, Castell Aragonés, Oristán y L'Alguer solicitando su apoyo en el envío de Montesanto. 19 de diciembre de 1700. ASCC, Sezione Antica, 84, f. 47. Carta de los consellers de Cagliari a Carlos III de Habsburgo de 30 de agosto de 1708. ASCC, Sezione Antica, 84, f. 107-108.
} 
proporcionar al enviado los argumentos que debía emplear en la audiencia con el rey y en las reuniones con los ministros y que debían servir como base para la redacción de uno o más memoriales. El documento de 1582 contiene un total de 18 capítulos mientras que el de 1621 contiene 35, por lo que la exposición de los negocios constituye la mayor parte de ambos documentos. Ello no nos debe sorprender ya que incluía una cantidad importante de información a menudo con referencias a privilegios, capítulos de corte o a la Carta de Logu.

Sin entrar en detalles sobre el contenido de ambas instrucciones para este estudio interesa especialmente el capítulo tercero del documento que la ciudad de Cagliari entregó a Armanyac dado que debía defender ante Felipe IV el derecho de la urbe a enviar síndicos al monarca, lo cual les había sido impedido por los virreyes en varias ocasiones.

"Ítem, attés lo recorrer los vassalls a son natural rey y senyor y als de son Consell és tant permés per tot dret axí natural com canònich y civil, més segnaladament se déu permetre dels regnes servits de mar y que están molt apartats y lluny de sa magestat y de son Real Consell com és lo present regne de Cerdenya. Se suplicarà a sa magestat que sia de son real servey concedir llisènsia als consellers y ciutadans de dita çiutat que sempre se lis offeresca occasió y tinga mester trametre síndich en cort per les coses que convingan a dita ciutat en benefissi e útil de aquella que ho pugan fer sens esperar ni demanar llisèntia als lloctinents de sa magestat per quant moltes voltes se offerex ocasió de representar algunes quexes contra de aquells y en aquella està clar que no lis dan. Ni menys parex ésser cossa convenient aguardar-la de sa magestat, tant per lo perill y dany de la tardansa com també perqué no parexerà a sa magestat ésser necessaria la transferitió de síndich se li podrá manar y ordenar los que serà de son real servey".

Asimismo, resulta interesante el capítulo décimo de las instrucciones a Otger de 1582 dado que se le encargaba informarse de los negocios que en la corte llevaba Joan Maria Serra, "síndich desta ciutat" que había sido enviado para suplicar al rey el decreto de los capítulos solicitados en las últimas Cortes. Por lo que se observa que la ciudad podía tener más de un representante en la corte para que tratasen asuntos distintos, lo que obligaba a los diferentes delegados a coordinarse y colaborar para obtener buen fin a sus negociaciones.

En definitiva los dos documentos analizados eran una guía que el enviado a la corte debía seguir por lo que como señala Bernabé (2007: 231-235) sobre las instrucciones a los embajadores de Orihuela su función era "formativa e informativa". Ya que se explicaba al enviado punto por punto lo que debía obrar y a su vez se le facilitaban los argumentos a emplear. A través de este tipo 
de documentos podemos comenzar a vislumbrar cual era la tarea de estos enviados a la corte, dado que solamente se les encargaba tratar con el monarca y unos pocos ministros, los del Consejo de Aragón, que podían influir en los decretos del soberano. Por lo demás se le proporcionaban testimonios que debía ordenar y repetir tanto en la audiencia con el rey como por escrito en memoriales y en las reuniones con los regentes del Consejo.

Estos documentos aportan un testimonio fundamental de por qué a pesar de la existencia de un aparato de representación permanente en la corte real, las ciudades sardas seguían empleando con regularidad el envío de emisarios extraordinarios al rey, dado que ello permitía que estuvieran más implicados en la resolución de los negocios y también aportaba más garantías sobre su desempeño que un agente permanente asalariado, cuya fidelidad podía ser más frágil y que no tenía más interés en el asunto que ganarse el sueldo.

\section{La continuación del mecanismo tras el cambio dinástico (siglos XVIII y XIX)}

Durante la Guerra de Sucesión española, la isla y reino de Cerdeña que se había mantenido vinculada a la Península Ibérica al formar parte de la Corona de Aragón durante más de cuatro siglos fue conquistada militarmente en dos ocasiones, primero por los austriacistas en 1708 y en 1717 por los borbónicos (Guia, 2007: 403-414; 2008: 67-90). Más tarde fue moneda de cambio en diferentes tratados internacionales y finalmente en 1720 fue a parar a manos de la dinastía Saboya (Mattone, 1992: 5-89). Los piamonteses ya antes de que se les cediese la isla, viendo que en algún momento podrían entrar a gobernarla, encargaron diferentes informes sobre el territorio sardo y sus formas de gobierno. En 1717 uno de ellos informaba al soberano saboyano: "Sette sono le città che si contengono in detto Regno, cioè Cagliari, Sassari, Oristano, Alguer, Boza, Castelaragonese et Iglesia, quali tutte sono immediatamente soggete al $\operatorname{Re}^{\prime \prime}$.

Estas ciudades se gobernaban mediante unos consellers y un Consejo General que actuaba como asamblea y en conjunto representaban la ciudad.

“Reppresentano l'università et il popolo e sopraintendono agli appalti ed alle provisioni delle vettovaglie con autorità di porvi sopra qualche gabella e fissare il prezzo ai commestibili, avendo in tali incidenza ampia autorità e giurisdizione col ius privativo al vicerè il che arriva dovendosi spedire sindaco e diputato al sovrano, al che non si può devenire senza il precedente consenso del vicerè; in questo particolare però, sendosi veduti in contrario como ne constano esempi stati approvati dal Supremo Consiglio nella Corte di Vienna". 
El autor daba como ejemplo de embajada el caso de don Emmanuel Ripoll quien había partido de la isla sin licencia del virrey para acudir como síndico de la ciudad de Cagliari en Viena, corte del emperador Carlos VI en aquel momento, también rey de Cerdeña como Carlos III (Del Piano, 1964: 175178). En ese documento, cuando se citaba al Supremo Consejo, ya no se hacía referencia al extinto Consejo de Aragón, sino al Consejo de España en Viena que había asumido las competencias de consejo real y tribunal supremo del reino de Cerdeña -que en los siglos anteriores había detentado el Consejo de Aragón.

El informe citado daba noticia a Vittorio Amedeo II de Saboya, futuro rey de Cerdeña, de los asuntos más importantes que se tenían que tener en cuenta a la hora de entrar a gobernar la isla, entre ellos estaba el funcionamiento de las instituciones delegadas del monarca, los arzobispados, la feudalidad, las universidades, la agricultura y por supuesto la representación política de los vasallos y de las ciudades reales. Estas urbes tenían amplia autoridad y jurisdicción para imponer gravámenes, fijar precios, regular el comercio, controlar el orden público, etc. Por diferentes cuestiones relativas a esas competencias los municipios podían enviar sus síndicos a tratar con el rey.

La situación descrita a principios del siglo XVIII, se podría aplicar a cualquier momento desde 1323 hasta 1847, si bien el reformismo saboyano introdujo algunas diferencias en la gestión municipal. Las bases institucionales puestas por los reyes de la Corona de Aragón en el proceso de conquista de la isla en los siglos XIV y XV se mantuvieron en esencia hasta la Perfetta Fusione con los territorios del Piamonte en 1847 (Sotgiu, 2018: 359-391). Tal vez la reforma de los Consigli Comunitativi en la década de 1760 fuese la que mayor impacto tuvo, pero aunque cambiase la planta del gobierno municipal no modificó sus competencias y las urbes sardas siguieron pudiendo enviar sus diputados al rey (Mattone, 1991a; Lepori, 2003: 92-173). De hecho, en la diputación que en 1773 hizo don Ignazio Aymerich, marqués de Láconi, a Turín entregó al rey Carlo Emmanuele III memoriales de las ciudades de Cagliari, L'Alguer, Castelsardo y de los apéndices de Cagliari. ${ }^{25}$ Esta diputación y su contenido, puede ser vista como una de las primeras reacciones de las élites sardas ante el reformismo de los Saboya y como un claro precedente de los eventos de la Sarda Rivoluzione de finales del siglo XVIII.

Por tanto, la historia de las ciudades del reino de Cerdeña y la del propio reino, en especial la que toca a la relación de los municipios con su soberano, quien también era su señor feudal, está repleta de eventos y circunstancias en que los burgos sardos tuvieron que enviar sus mensajeros a su rey. Estamos pues ante un mecanismo de uso plurisecular. Más allá de cambios en la dinastía

${ }^{25}$ ASCC, Aymerich, Stamento Militare, B. 10, 11 y 12. 
gobernante y en la corte de referencia los fundamentos jurídicos en que se basaban siguieron siendo los mismos. De modo que allí donde estuviese el rey de Cerdeña, ya fuera en Barcelona, Zaragoza, Valencia, Nápoles, Madrid, Viena, Turín o la propia Cagliari los embajadores y síndicos de las ciudades sardas defendieron los privilegios que habían conquistado durante los siglos precedentes bajo las diferentes dinastías y no dudaron en presentar ya en el siglo XIX legislación que les había sido otorgada en el siglo XIV durante la campaña de conquista de los reyes de la Corona de Aragón.

En 1831 la ciudad de L'Alguer enviaba a Turín una rappresentanza con el fin de reivindicar dos antiquísimos privilegios de 1361 y 1444 respectivamente. Sobre ello se consultó al Consejo de Cerdeña, que no era otra cosa que la adaptación del Consejo de Aragón en Turín puesto que las leyes sardas obligaban a la existencia de tal organismo. Los consejeros consideraban aun entonces "necessaria l'osservanza dei privilegi" (Mattone, 1994: 281). Este ejemplo muestra la continuidad y la vigencia de los privilegios y estatutos municipales sardos y también la pervivencia del derecho de las ciudades sardas de acudir al rey y su Consejo para solicitar su observancia y en definitiva el buen gobierno de las urbes.

No se debe ver en el uso plurisecular de este mecanismo una particularidad sarda, pues lo mismo sucedió en muchos otros territorios. Sin embargo, dentro de la Corona de Aragón sí lo fue en el sentido de que los cambios dinásticos, que separaron finalmente Cerdeña del resto de reinos, permitieron la continuidad institucional y legislativa, dado que la Nueva Planta sarda tuvo solo una aplicación muy breve y los Saboya recibieron la isla con la condición de conservar sus modos de gobierno (Bermejo, 1979-1980; Maqueda, 2004-2006). De todos los territorios que formaban parte de la Corona de Aragón bajo la casa de Austria -aquellos gobernados desde el Consejo de Aragón- en el siglo XIX el único que seguía manteniendo sus instituciones, leyes y formas de gobierno era el reino de Cerdeña, por tanto, se registra una continuidad de cinco siglos, una situación excepcional en la historia de la Corona de Aragón. Sin embargo, en los otros territorios de la extinta Corona de Aragón, aunque habían perdido sus leyes y privilegios, la necesidad de contacto con la corte y con el soberano seguía existiendo, de manera que aunque se hubiesen abolido las leyes que garantizaban el derecho a enviar embajadas al rey, estas representaciones continuaron con otros nombres y por otras vías. Al fin y al cabo, en las ciudades que permanecieron en la Monarquía hispánica se aplicaron las leyes municipales castellanas que aseguraban poder acudir mediante procuradores a la corte. 


\section{Algunos apuntes finales}

A lo largo de las páginas anteriores se ha hecho un somero recorrido por más de cinco siglos de comunicaciones entre las ciudades de la isla y reino de Cerdeña con su soberano, casi siempre lejano y ausente. Con ello se hace patente la necesidad de las urbes sardas de estar en contacto con su rey y señor, pervivencia de un mecanismo como el de enviar a un portavoz con poderes para que tratase con él.

A tenor de las investigaciones que están viendo la luz, debemos pensar que recurrir a nuncios, procuradores, síndicos, agentes, embajadores $\mathrm{o}$ diputados para tratar con el soberano fue una práctica común entre las administraciones municipales y otros muchos organismos y particulares. Por consiguiente, no se debe ver una particularidad de las urbes sardas en ello. Sin embargo, lo que resulta especial en el caso de las ciudades reales del Reino de Cerdeña es la continuidad legislativa a lo largo de los siglos, cosa que no sucedió con el resto de la Corona de Aragón, cuya trayectoria acabó con la Guerra de Sucesión. Ello permite observar que en un periodo de más de medio milenio el mecanismo fue básicamente el mismo, aunque modernizándose o quedándose obsoleto según el momento. Conviene recordar que los deputati enviados a Turín en los siglos XVIII y XIX debían ser recibidos y tratados como lo habían sido los embajadores y síndicos enviados a Madrid en los siglos XVI y XVII, que a su vez habían heredado costumbres de los siglos anteriores. Por lo que es posible pensar que en ocasiones estas cuestiones dificultasen más que ayudasen, dado que no eran fruto del tiempo en que se vivía, sino de un contexto muy anterior.

En todo caso, las siete ciudades reales tuvieron siempre derecho a hacerse presentes a los ojos de su rey, de quien, como cabeza de la república, dependía el gobierno y la justicia. Como solía recordarse a los soberanos, la conservación y aumento de las ciudades iba en beneficio del rey, en palabras de Melchor Dexart ${ }^{26}$, síndico de la ciudad de Cagliari enviado a Felipe III en 1603, la aceptación de los capítulos suplicados "convé al servey de Vostra Magestat, bé y augment de la dita ciutat y habitadors d'ella". Por lo que los vasallos acudiendo a besar las reales manos no podían esperar otra cosa que el consuelo de sus aflicciones "que ultra ser totes coses convenients ho rebrà dita ciutat a molt singular merced de Vostra Magestat" (Doneddu, 2015: 1308-1309).

\footnotetext{
${ }^{26}$ Melchor Dexart además de conseller en cap de Cagliari y síndico enviado a la corte fue el padre de don Joan Dexart uno de los más importantes juristas sardos de la época moderna (Mattone, 1991B).
} 


\section{Bibliografía citada}

Álvarez-Ossorio Alvariño, Antonio (1997). "Pervenire alle orecchie della maestà": el agente lombardo en la corte madrileña", Annali di storia moderna e contemporánea, 3, pp. 173-223.

Álvarez-Ossorio Alvariño, Antonio (2000). “Ceremonial de palacio y constitución de monarquía: las embajadas de las provincias en la corte de Carlos II", Annali di storia moderna e contemporánea, 6, pp. 227-358.

Anatra, Bruno (1987). La Sardegna dall'Unificazione aragonese ai Savoia, Torino: UTET.

Anatra, Bruno (2008). "Les institucions urbanes de Sardenya a l'Antic Règim", Afers: fulls de recerca i pensament, vol. 23, núm. 59, pp. 21-28.

Angulo Morales, Alberto (2010). "Embajadores, agentes, congregaciones y conferencias: la proyección exterior de las provincias vascas (siglos XV-XIX)", Delegaciones de Euskadi (1936-1975). Antecedentes históricos de los siglos XVI al XIX, origen y desarrollo, Vitoria-Gasteiz: Lehendakaritza, pp. 23-87.

Angulo Morales, Alberto (2016). "Ciudades, villas y territorios. La representación de las tres provincias vascas en la corte en tiempos de los Austrias" en Carvajal, David Vitores, Imanol y Añibarro, Javier (eds.) Poder, Fisco y Mercado en las ciudades de la Península Ibérica (siglos XIV-XVI), Valladolid: Castilla ediciones, pp. 241-257.

Angulo Morales, Alberto (2019). “Ubicarse en la corte. La presencia institucional diplomática vasca en el corazón de la Monarquía Hispánica”, Martínez Millán, José; Sánchez Belén, Juan Antonio y Rivero Rodríguez, Manuel Del enfrentamiento a la amistad. Influencias entre las monarquías de Francia y España en los siglos XVII y XVIII, Madrid: Polifemo, pp. 427-458.

Arrieta Alberdi, Jon (1994). El Consejo Supremo de la Corona de Aragón (14941707), Zaragoza: Institución Fernando el Católico.

Belenguer Cebriá, Ernest (2012). Fernando el Católico y la ciudad de Valencia, Valencia: Publicacions de la Universitat de València [Primera edición: València en la crisi del segle XV, Barcelona: Edicions 62].

Bermejo Cabrero, José L. (1979-1980). “Un decreto más de nueva planta”, Revista de derecho político. UNED, 5, pp. 129-144.

Bernabé Gil, Bernabé (2008). "Las embajadas municipales como ámbito de relación política con la corona al margen de las Cortes" en Ferrero, Remedios y Guia, Lluis (eds.) Corts i parlaments de la Corona d'Aragó. Unes institucions emblemàtiques en una monarquia composta, València, pp. 429-444. 
Boscolo, Alberto (1993). "I parlamenti di Alfonso il Magnanimo", en Boscolo, Alberto y Schena, Olivetta (eds.) Acta Curiarum Regni Sardiniae. 3. Cagliari: Consiglio Regionale della Sardegna, pp. 15-75.

Calvo Rodríguez, Manuel (1993). “Embajadas y embajadores de Barcelona enviados a la Corte en la segunda mitad del siglo XVII", Pedralbes: Revista d'història moderna, 13-1, pp. 535-544.

Casula, Francesco (2016). Carlo Felice e i tiranni sabaudi, Dolianova (Cagliari): Parteolla.

Casula, Francesco Cesare (1984). Sardegna calano-aragonese. Profilo storico, Roma: Editrice Mediterranea.

Catani, Giuseppina y Ferrante, Carla (2004). Acta Curiarum Regni Sardiniae. 23. Il Parlamento del viceré Giuseppe de Solís Valderribano conte di Montellano (1698-1699), Cagliari: Consiglio Regionale della Sardegna.

D’Agostino, Guido (2009). Acta Curiarum Regni Sardiniae. 21. Il Parlamento del viceré Francesco de Benavides conte di Santo Stefano (1677-78), Cagliari: Consiglio Regionale della Sardegna.

Del Piano, Lorenzo (1964). "Una relazione inedita sulla Sardegna nell 1717", Archivio Storico Sardo, XXIX, pp. 159-192.

Doneddu, Giuseppe (2015). Acta Curiarum Regni Sardiniae. 13. Il Parlamento del viceré Antonio Coloma conte di Elda (1602-1603), Sassari: Consiglio Regionale della Sardegna.

Ferrante, Carla (2007). "Le istituzioni municipali di Castellaragonese (secoli XVXVII)", A. Mattone y A. Soddu (coords.) Castelsardo. Novecento anni di storia, Roma: Carocci, pp. 541- 574.

Floris, Francesco (1999). Storia della Sardegna, Roma: Newton \& Compton editori.

Fossati Raiteri, Silvana (2007). "Catalani e Genoveso tra Bonifacio e Castelgenovese (1421-58)", Mattone, Antonello y Soddu, Alessandro (coords.) Castelsardo. Novecento anni di storia, Roma: Carocci, pp. 439-447

Francioni, Federico (2015). Acta Curiarum Regni Sardiniae. 22. Il Parlamento del viceré Nicola Pignatelli duca di Monteleone (1688-1689), Sassari: Consiglio Regionale della Sardegna.

Fuertes Broseta, Miquel (2019). "Les ambaixades a la cort. Un mecanisme amb diferent execució a València, Sardenya i Catalunya", Dantí, Jaume; Gil, Xavier; Sola, Diego; Mauro, Ida (coords.) Actes del VIII Congrés d'Història Moderna de Catalunya: «Catalunya i el Mediterrani». Barcelona, 17-20 desembre 2018, Barcelona: Area d'Història Moderna Universitat de Barcelona, pp. 876-895. 
Galoppini, Laura (2016). Acta Curiarum Regni Sardiniae. 6. I Parlamenti dei viceré Angelo de Vilanova (1518 - 1523 e 1528), Cagliari: Consiglio Regionale della Sardegna.

Gil Pujol, Xavier (2016). La fábrica de la monarquía. Traza y conservación de la monarquía de España de los reyes católicos y los Austrias, Madrid: Real Academia de la Historia.

Guia Marín, Lluís (2007). "Ruptura i continuitat de la Corona d'Aragó. L'impacte de la Guerra de Successió", Morales, Mercé; Renom, Mercé y Cisneros, Mamés L'aposta catalana a la Guerra de Successió (1705-1707), Barcelona, Museu d'Història de Catalunya, pp. 403-414.

Guia Marín, Lluís (2008). “Un regne sense Corts. Sardenya en la cruilla dels canvis dinàstics de la Guerra de Successió", Afers: fulls de recerca i pensament, vol. 23, núm. 59, pp. 67-90.

Guia Marín, Lluís (2016). “Pervivencia y ruptura de la tradición jurídico-política de la Corona de Aragón en las ciudades reales del Reino de Cerdeña (siglos XVXVIII)", Meloni, Maria Giuseppina; Oliva, Anna Maria y Schena, Olivetta Ricordando Alberto Boscolo. Balanci e prospettive storiografiche, Roma: Viella, pp. 385-406.

Herrero Sánchez, Manuel (2017). “La Monarquía Hispánica y las repúblicas europeas. El modelo republicano en una monarquía de ciudades" en Herrero, Manuel (ed.) Repúblicas y republicanismo en la Europa moderna (siglos XVI-XVIII), México DF: Fondo de Cultura Económica, pp. 273-283.

Lalinde Abadía, Jesús (1982). "La instrumentalización del pluralismo en la Corona de Aragón", Bolletí de la Societat Arqueològica Lul-liana. Revista d'estudis històrics, núm. 39, pp. 29-50.

Lalinde Abadía, Jesús (1994). "L'influenza dell'ordinamento politico-giuridico catalano in Sardegna" en Mattone, Antonello y Sanna, Piero (coord.) Alghero la Catalogna il Mediterraneo, Sassari: Gallizzi, pp. 273-279.

Lalinde Abadía, Jesús (1994). “El significado de la Corona de Aragón (contrarréplica)", Medievalia, 11, pp. 31-38.

Lalinde Abadía, Jesús (1997). “Depuración histórica del concepto de Corona de Aragón", Serrano, Eliseo y Sarasa, Esteban La Corona de Aragón y el Mediterráneo: siglos XV-XVI, Zaragoza, pp. 433-460.

Lepori, Maria (2003). Dalla Spagna ai Savoia. Ceti e corona nella Sardegna del Settecento, Roma: Carocci.

Manconi, Francesco (1998). “'De no poderse desmembrar la Corona de Aragón’. Sardenya i Països Catalans, un vincle de quatres segles", Pedralbes: revista d’història moderna, núm. 18-2, pp. 179-194. 
Manconi, Francesco (2010). Cerdeña, un reino de la Corona de Aragón bajo los Austria, Valencia: Publicacions Universitat de València.

Manconi, Francesco (2012a). Una piccola provincia di un grande impero. La Sardegna nella Monarchia composita deglia Asburgo (secoli XV-XVIII), Cagliari: CUEC.

Manconi, Francesco (2012b). Tener la patria gloriosa. I confliti municipali nella Sardegna spagnola, Cagliari: CUEC.

Maqueda Abreu, Consuelo (2004-2006). “Entorno al decreto de Nueva Planta de Cerdeña. 1717-1720", Ius fugit: Revista interdisciplinar de estudios históricojurídicos, 13-14, pp. 439-477.

Marongiu, Antonio (1979). I parlamenti sardi. Studio storico, istituzionale e comparativo, Milano: Giuffrè.

Mattone, Antonello (1986). “Gli Statuti sassaresi nel periodo aragonese e spagnolo", en Mattone, Antonello y Tangheroni, Marco (a cura di) Gli Statuti Sassaresi. Economia, Società, Instituzioni a Sassari nel Medioevo e nell'Eta' Moderna, Sassari: Edes, pp. 409-490.

Mattone, Antonello (1991a). "Istituzioni e riforme nella Sardegna del Settecento", Dal trono all'albero de la libertà, Atti del convengno Torino 11-13 settembre 1989, Roma: Ministero per i Beni Culturali e ambientali, pp. 325-412.

Mattone, Antonello (1991b). "Giovanni Dexart", Dizionario Biografico degli Italiani, vol. 39 [en línea] https:/www.treccani.it/enciclopedia/giovannidexart \%28Dizionario-Biografico\%29/

Mattone, Antonello (1992). "La cessione del regno di Sardegna dal trattato di Utrech alla presa di possesso sabauda (1713-1720)", Rivista storica italiana, CIV-I, pp. 5-89.

Mattone, Antonello (1994). "I privilegi e le istituzioni municipali di Alghero (XIV-XVI secolo)" en Mattone, Antonello y Sanna, Piero (coord.) Alghero la Catalogna il Mediterraneo, Sassari: Gallizzi, pp. 281-310.

Mauro, Ida (2020). "La rete diplomatica delle capitali senza re. Il sistema di 'delegazioni interne' della monarchia spagnola", Cancilla, Rossella Capitali senza re nella monarchia spagnola. Realità, relazioni, immagini (sec. XVI-XVIII), Palermo: Mediterranea, pp. 471-494.

Murgia, Giovanni (2006). Acta Curiarum Regni Sardiniae. 18. Il Parlamento del viceré Fabrizio Doria duca di Avellano (1641-1643), Cagliari: Consiglio Regionale della Sardegna.

Oliva, Anna Maria (2005). “Memorial de totes les coses que ha a fer, dir, applicar, per la universitat de Càller davant lo senyor rey: ambasciatori della città di Cagliari alla corte catalano-aragonese nell Quattrocento. Prime note", 
Narbona, Rafael (coord.) La Mediterrània de la Corona d'Aragó, segles XIII-XVI i VII Centenari de la Sentència Arbitral de Torrellas, 1304-2004. XVIII Congrès d'Història de la Corona d'Aragó, Vol. 1, Valencia: Publicacions Universitat de València, pp. 327-348.

Oliva, Anna Maria y Schena, Olivetta (1998). Acta Curiarum Regni Sardiniae. 5. I Parlamenti dei viceré Giovanni Dusay e Ferdinando Girón de Rebolledo (1495, 1497, 1500, 1504-1511), Sassari: Consiglio Regionale della Sardegna.

Ortu, Gian Giacomo (2017). La Sardegna tra Arborea e Aragona, Nuoro: Il Maestrale.

Palomo Reina, Cristian (2020). “Noves perspectives per a una qüestió no resolta: Per qué Catalunya fou un principat i no un regne?", Anuario de estudios medievales (50/1), pp. 323-352.

Pergola, Andrea (2020). Corrispondenza del Regnum Sardiniae et Corsicae nelle Cartas Reales di Alfonso il Magnanimo dell'Archivo de la Corona de Aragón. Un nuovo strumento per la ricerca, Cagliari: Università di Cagliari, tesis doctoral.

Pinna, Michele (1903). Indice dei documenti cagliaritani del Regio Archivio di Stato dal 1323 al 1720, Tipo-Litografia commerciale, Cagliari.

Reglá Campistol, Joan (1973). Aproximació a la historia del País Valencià, Valencia: Ed. 3 i 4.

Sorgia, Giancarlo y Todde, Giovanni (1981). Cagliari. Sei secoli di amministrazione cittadina, Cagliari: Lions.

Sotgiu, Girolamo (2018). Storia della Sardegna Sabauda. 1720-1847, Nuoro: Il Maestrale [Primera edición: (1984) Roma-Bari: Laterza].

Tasca, Cecilia (1999). Titoli e privilegi dell'Antica Città di Bosa, Cagliari: Comune di Bosa.

Tasca, Cecilia (2012). Bosa città regia. Capitoli di Corte, Leggi e regolamenti (14211826), Roma: Carocci.

Uccheddu, Franca (1998). Il "Llibre de regiment" e le pergamene dell'Archivio Comunale di Oristano (Secc. XV-XVII), Oristano: Editrice s'alvure.

Vicens Vives, Jaume (1936-1937). Ferran II i la Ciutat de Barcelona 1479-1516, Barcelona: Emporium, 3 vols.

Vico y Artea, Francisco de (1639). Quinta parte de la Historia General de la Isla y Reyno de Sardeña, Barcelona.

Vico y Artea, Francisco de (1714). Leyes y pragmáticas reales del reyno de Sardeña, Cagliari: Juan Bautista Galcerín. 